\title{
Knowledge, Practice and Utilization of Dental Services among Pregnant Women in the North of Jordan
}

\author{
'Zain A Malkawi, ${ }^{2}$ Reem S Tubaishat
}

\section{ABSTRACT}

Aim: The aim of this study was to evaluate women's oral hygiene knowledge, practice, and use of dental services during pregnancy in the north of Jordan.

Materials and methods: Voluntary sample of 154 pregnant women of 18 to 40 years old were invited to participate in the study. They were asked to read a self-designated questionnaire and a cover letter which explained the purpose of the study. The questionnaire addressed self-reported demographics, knowledge, practice and use of dental services during pregnancy. Data were statistically analyzed using Chi-square test to determine statistically significant differences across knowledge, practice and use of dental services during pregnancy.

Results: The sample included $29.3 \%$ aged 20 to 24 years old; $33.1 \%$ having bachelor degree; and $66.9 \%$ were housewives. The majority of study sample $68.2 \%$ knew they need dental consultation during pregnancy; however, $39.5 \%$ received dental consultation during pregnancy. Majority $62.4 \%$ brushed their teeth regularly; however, $73.2 \%$ does not use auxiliary dental hygiene devices. Majority $44.5 \%$ visited dentist, when they feel pain. Statistically significant association were found between educational level and knowledge about need to dental consultation during pregnancy $(p=0.012$ ); educational level and knowledge about link between pregnancy and periodontal diseases ( $p=0.01$ ); and economic status and use of auxiliary dental hygiene devices during pregnancy $(p=0.040)$.

Conclusion: Pregnant women brushed their teeth regularly and visited dentist occasionally. Income was significantly associated with increase use of auxiliary dental hygiene devices. Educational level was significantly associated with mothers' knowledge about the need for consultation and possible link between pregnancy and periodontal diseases.

Keywords: Pregnancy, Oral hygiene practice, Dental care utilization, Dental knowledge.

How to cite this article: Malkawi ZA, Tubaishat RS. Knowledge, Practice and Utilization of Dental Services among Pregnant Women in the North of Jordan. J Contemp Dent Pract 2014;15(3):345-351.

\footnotetext{
${ }^{1}$ Dean Assistant Instructor, ${ }^{2}$ Instructor

${ }^{1,2}$ Department of Allied Dental Sciences, Faculty of Applied Medical Sciences, Jordan University of Science and Technology, Irbid, Jordan

Corresponding Author: Zain A Malkawi, Dean Assistant Instructor, Department of Allied Dental Sciences, Faculty of Applied Medical Sciences, Jordan University of Science and Technology, Irbid, Jordan, e-mail: malkawiz@just.edu.jo
}

\section{Source of support: Nil}

Conflict of interest: None declared

\section{INTRODUCTION}

Daily oral hygiene and routinely dental visits are important issues of oral health care. Pregnancy is a natural process that may create few oral and dental changes. Hajikazemi et al ${ }^{1}$ reported that during pregnancy, hormone balances change and most of women will experience some signs of pregnancy gingivitis if good oral hygiene is not practiced. Morning sickness and most of pregnant women cannot tolerate the smell or taste of toothpastes, that may play a significant role in causing pregnancy gingivitis. ${ }^{2}$

Through the clinical dental hygiene practice of the principal investigators of this study, it is obvious that many of Jordanian pregnant women may read about the importance of practicing good oral hygiene and receiving dental services during pregnancy, but they may not know why oral hygiene is important. And there is still paucity in the literature about Jordanian pregnant womens oral hygiene knowledge, practice, and dental services utilization during pregnancy. Therefore, the purpose of this study was to evaluate self-reported pregnant women's oral hygiene knowledge, practice, and use of dental services during pregnancy in a sample of Jordanian women and to study factors related knowledge, practice, and dental visits during pregnancy in the north of Jordan.

\section{Oral Hygiene Knowledge and Practice during Pregnancy}

During pregnancy hormone balances will change which will create a significant oral problems if good oral hygiene is not practiced. ${ }^{1}$ Regular dental care is important to improve pregnancy outcomes as well as a significant comfort for the women. Wrzosek and Einarson ${ }^{3}$ found that presenting periodontal treatment, administrating of local anesthesia, amalgams and X-rays scans have no increased risk to the developing fetus. Therefore, all those are useful in maintaining optimal oral health for the mother and the baby.

Hamissi J et al, ${ }^{4}$ in 2009 conducted a study on 760 pregnant women to describe the knowledge and attitude of pregnant women in Qazvin Province, central Iran, relating to oral hygiene. They reported that the majority 
of the participants $73.1 \%$ brushed their teeth at least twice a day. Sixty-one percent of participants had never been advised by their doctor to see a dentist. They concluded that health authorities should strengthen the implementation of community-based oral disease prevention and health promotion programs.

Hajikazemi et $\mathrm{al}^{1}$ explored the relationship between women's knowledge, attitude, and practice on oral and dental care during pregnancy. They reported that $5.6 \%$ of women had high knowledge about oral and dental care, and $34.4 \%$ had good practice on oral and dental care. Therefore, researchers concluded that women should be educated and motivated to maintain a high level of oral hygiene prior to and throughout pregnancy.

Using a cross-sectional survey, Alwaeli et $\mathrm{al}^{5}$ in 2005 investigated the degree of periodontal health knowledge, and awareness of 16 to 45 years old Jordanian pregnant women. They reported that a minority of the pregnant women $(16.4 \%)$ had knowledge or ability to identify dental plaque, while most of them $88 \%$ were aware that bleeding gums indicated the presence of periodontal disease. The researchers recommended providing pregnant women with simple educational preventive programs on oral self-care during pregnancy.

A study was conducted by Thomas et $\mathrm{al}^{6}$ in 2008; which surveyed 445 women in the postnatal ward at the Women's and Children's Hospital, Adelaide reported that $82 \%$ of the participants did not know about periodontal diseases, and $91 \%$ of the participants brushed their teeth one or more time a day, while half of the surveyed women used dental floss weekly or more. Researchers recommended more intensive dental health education in pregnancy can lead to maintain oral health.

\section{Utilization of Dental Services during Pregnancy}

A study by Gaffield et $\mathrm{al}^{7}$ showed that most mothers who recently delivered live-born infants did not go to receive dental care during their pregnancy. Based on that, they recommended establishing guidelines that could benefit maternal oral health and prenatal outcomes. Boggess et $\mathrm{al}^{8}$ conducted a survey on 599 pregnant women to evaluate women's oral hygiene practices and dental care utilization during pregnancy. They reported $74 \%$ of the participants having received no regular dental care during pregnancy, on the other hand, Hispanic women were significantly less than were White or African-American women to receive routine dental care during pregnancy. Researchers found that the existing of the relationship between economic, racial and ethnic disparities and oral hygiene practices and dental services utilization during pregnancy.

In a study by Jiang et $\mathrm{al}^{9}$ aimed to compare dental services used by women before, during and after pregnancy.
Researchers found that women during pregnancy tended to visit dentist less regularly than before pregnancy $(\mathrm{p}<0.001)$ compared with their using during pregnancy, and women after pregnancy their using for dental services increased significantly $(p<0.001)$. Researchers predicted that those women and their dentists use dental services only for conservative purposes during pregnancy, otherwise postponing their use until after give a birth.

A study conducted by Habashneh et $\mathrm{al}^{10}$ in 2005 to assessed knowledge, behaviors, and attitudes toward dental care during pregnancy of 625 women who had given birth in Johnson County, Iowa. They found only $49 \%$ of the respondents reported visiting dentist during pregnancy. Based on that, researchers recommended increasing education of the importance of dental care before and during pregnancy.

In a survey that conducted by Lydon-Rochelle et al ${ }^{11}$ in 2004, researchers found $59 \%$ of the surveyed women reported no dental use during pregnancy. Therefore, they concluded that there is a significant need to enhance education and training maternity care providers about oral health and pregnancy. In addition to, a study which was conducted by Dinas et $\mathrm{al}^{12}$ in 2007 , which surveyed 425 women in Northern Greece stated that some of the participants $27.3 \%$ visited dentist during their pregnancy. Based on that, researchers recommended offering oral health education for women of reproductive age.

\section{Our Research is based on the Following Null Hypotheses}

1. Highly educated pregnant women would report less knowledge about need to dental consultation during pregnancy than less educated pregnant women.

2. Highly educated pregnant women would report less knowledge about the possible link between pregnancy and periodontal diseases than less educated pregnant women.

3. Pregnant women with high income would report less using for the auxiliary dental hygiene devices than pregnant women with less income.

4. Pregnant women with high income would report less using for dental services than pregnant women with less income.

5. Pregnant women with health insurance would report less using for dental services than pregnant women with no health insurance.

\section{MATERIALS AND METHODS}

Arrangements for data collection were approved by the directors of health clinics. The sample included a total of 154 pregnant women aged between 18 and 40 years old; 
who sought prenatal care at public health clinics and at private clinics in the city of Irbid, Jordan. Questionnaires with cover letter were distributed to women in the clinics during the period of 4 weeks. Volunteers were asked to read information in the cover letter and were allowed to see the questionnaire before they decided to participate. Volunteers were asked to complete the questionnaire; they were then collected and returned to the principal investigator.

Because, the questionnaire was self designed, content validity was established by a panel of dental health sciences faculty experts at Jordan University of Science and Technology. Test-retest reliability was also documented by administrating the questionnaire twice to the same 10 women within 1 week. Given multiple choice and numeric open end questions were created. Participants were asked to select one and sometimes more than one response regarding their perceived oral hygiene knowledge, practice, and utilization of dental services during pregnancy. Items in the questionnaire included: demographics; oral hygiene knowledge and practice during pregnancy; and the utilization of dental services during pregnancy.

Knowledge, practice and utilization of dental services among pregnant women in the North of Jordan Questionnaire

Directions: Please answer each question by checking $(\checkmark)$ the answer that Best reflects your own beliefs and practices. After completing the questionnaire, please return the completed questionnaire to the person who distributed it to you. The questionnaire takes about 10 minutes to complete, and all the information will remain confidential only for research purpose. Thank you

Section I. Demographics:

1. Age:

$\begin{array}{lll}\square<20 & \square 20-24 & \square 25-29 \\ \square \geq 35\end{array}$

2. Age ...

3. Education:

$\begin{array}{ll}\square<\text { High school } & \square \text { High school } \\ \square \text { Diploma } & \square \text { Bachelor } \\ \square>\text { Bachelor } & \end{array}$

4. Total family income per month:
$\square<200 \mathrm{JD}$
$\square 200 \leq 400 \mathrm{JD}$
$\square 400 \leq 600 \mathrm{JD}$
$\square 600 \leq 800 \mathrm{JD}$
$\square \geq 800 \mathrm{JD}$

5. The total number of the family members is:

6. Prenatal care payer:

$\square$ Insurance $\square$ Self-pay $\square$ Military $\square$ Others

7. Occupation:
$\square$ Housewife
$\square$ Employee

8. Prenatal care site:
$\square$ Private physician
$\square$ Hospital clinic
$\square$ Health centers
$\square$ Others

9. How many children do you have?
$\square$ This is my first child
$\square$ One
$\square$ Two
$\square$ Three
$\square$ Four
$\square$ Five
$\square>$ Five

10. You are at what preterm of pregnancy?
$\square$ First (1-3 months)
$\square$ Second (4-6 months)
$\square$ Third (7-9 months)

Section II. Knowledge and practice of oral hygiene during pregnancy:

\section{A: Knowledge}

11. Do you know that you in need to dental consultation during pregnancy?
$\square$ Yes
$\square$ No

12. Did you have a dental consultation during pregnancy?
$\square$ Yes
$\square$ No

13. If yes, please specify who tell you that you need a dental consultation during pregnancy?
$\square$ Your physician
$\square$ Dentist
$\square$ Family members
$\square$ Peers
$\square$ Media/TV advertisements $\square$ Others

14. Do you know if there is a relationship between periodontal diseases and pregnancy outcomes?
$\square$ Yes
$\square$ No
$\square$ I do not know

15. Do you know if there is a relationship between hormonal changes during pregnancy and oral health status?
$\square$ Yes
$\square$ No
$\square$ I do not know

16. If yes in 14 and 15 , please mention the source of these information that you got from

$\square$ Book/magazine/brochure

$\square$ Mentioned during my prenatal care

$\square$ Dentist told me $\quad \square$ Others

17. Are you smoker?
$\square$ Yes
$\square$ No

18. If yes, have you stopped smoking because of pregnancy?
$\square$ Yes
$\square$ No

B: Practice

19. Do you brush your teeth regularly?
$\square$ Yes
$\square$ No
$\square$ Sometimes

20. Specify the number of times of your teeth brushings $\square$ More than once a week $\square$ Not everyday $\square$ Once per day

$\square$ Twice or more per day

21. Do you use auxiliary dental hygiene devices, such as dental floss?
$\square$ Yes
$\square$ No

22. If yes, how often do you use them?
$\square$ Once per day
$\square$ Once per week
$\square$ More than once a week
$\square$ Occasionally

Section III. Utilization of dental services during pregnancy:

23. How often do you visit dentist during pregnancy?
$\square$ Every 3 months
$\square$ Every 6 months
$\square$ When I feel pain
$\square$ I do not visit dentist 
24. If you visit dentist, what was the treatment you received during pregnancy?
$\square$ Fillings
$\square$ Taking X-ray
$\square$ Extraction
$\square$ Scaling/R/P
$\square$ Polishing
$\square$ Others

25. If you do not visit dentist during pregnancy, can you specify why?
$\square$ No time
$\square$ I do not need
$\square$ Difficult transportation $\square$ Cost
$\square$ Dental clinic is away from home
$\square$ Because of pregnancy $\square$ Others

26. If your choice in the previous question is 'Because of pregnancy', please specify why Thank You.

The results are generalized to Jordanian pregnant women, who are similar to those represented in this study.

\section{Statistical Treatment}

Data were statistically analyzed using statistical software (SPSS for Windows, 16.0; SPSS, Inc, Chicago, III). Frequencies and percentages were used to summarize categorical data. Chi-square was used to analyze nominal data and most of the demographic data to determine statistically significant difference across the subject's selfreport oral hygiene knowledge, practice and utilization of dental services during pregnancy. Analyzes employed frequency distributions and bar graphs. A p-value $\leq 0.05$ was considered significant.

\section{RESULTS}

A total number of 155 questionnaires were distributed; and 154 of the forms were completed by volunteering pregnant women. This account for a return rate of $99.4 \%$. According to demographics, the results indicated that the majority of respondents $29.3 \%$ were between 20 and 24 years old, $12.0 \%$ were $\leq 20$ years old, and $9.3 \%$ were $\geq 35$ years old, and according to the educational level of the participants; the majority $33.1 \%$ having a bachelor degree, while $12.6 \%$ having less than high school of education. In terms of economic status, the majority of volunteers $7.8 \%$ earned as a total family income by month $\leq 800$ Jordanian Dinars (JD); and only $11.1 \%$ earned $\leq 200$ JD monthly.

Self-reported results showed that almost $68.2 \%$ of pregnant women knew that they need dental consultation during pregnancy, however, almost one-third of the participants $31.8 \%$ do not know. On the other hand, 39.5\% of pregnant women have received dental consultation during pregnancy; however, $60.5 \%$ did not receive consultation during their pregnancy. In terms of practicing of oral hygiene during pregnancy almost $62.4 \%$ of pregnant women brush their teeth regularly during pregnancy, on the other hand, one third of the participants use auxiliary dental hygiene devices during pregnancy. The frequencies of dental visits, type of dental services received, and the reasons for not visiting dentist during pregnancy are summarized in Table 1.

Null hypothesis 1: Highly educated pregnant women would report less knowledge about need to dental consultation during pregnancy than less educated pregnant women.

Null hypothesis 1 was rejected as Chi-square analysis showed a statistically significant relationship between educational level and knowledge about the importance of dental consultation during pregnancy $(\mathrm{p}=0.012)$.

Table 1: Utilization of dental services during pregnancy

\begin{tabular}{lll}
\hline Variable & $N$ & $\%$ \\
\hline Frequency of dental visits: & & \\
Every 3 months & 7 & 4.8 \\
Every 6 months & 65 & 44.5 \\
when I feel pain & 61 & 41.8 \\
I do not visit the dentist during pregnancy & & \\
When visiting the dentist what services did you receive? & 51 & 45.5 \\
Filling & 4 & 3.6 \\
X-ray & 16 & 14.3 \\
Extraction & 25 & 22.3 \\
Scaling & 8 & 7.1 \\
Whitening & 8 & 7.1 \\
Others & & \\
Reasons for not visiting dentist during pregnancy & 20 & 14.4 \\
No time & 29 & 42.4 \\
No need & 4 & 2.9 \\
Distant clinic & 6 & 4.3 \\
Difficulty in transportation & 8 & 5.8 \\
Expensive costs & 32 & 23 \\
Because of pregnancy & 10 & 7.2 \\
Others & & \\
\hline
\end{tabular}


Table 2: Association between educational level and reported need for dental consultation

\begin{tabular}{|c|c|c|c|c|c|}
\hline \multicolumn{6}{|c|}{ Do you know that you need dental consultation during pregnancy? } \\
\hline \multirow[t]{2}{*}{ Educational level } & \multicolumn{2}{|c|}{ Yes } & \multicolumn{2}{|c|}{ No } & \multirow[t]{2}{*}{ p-value } \\
\hline & $N$ & $\%$ & $N$ & $\%$ & \\
\hline Less than high school & 8 & 42.1 & 11 & 57.9 & \\
\hline High school & 26 & 63.4 & 15 & 36.6 & \\
\hline Diploma & 21 & 65.6 & 11 & 34.4 & 0.012 \\
\hline Bachelor & 39 & 78 & 11 & 22 & \\
\hline Higher education & 9 & 100 & 0 & 0 & \\
\hline
\end{tabular}

Table 3: Association between educational level and knowledge of the possible link between pregnancy and periodontal diseases

\begin{tabular}{|c|c|c|c|c|c|c|c|c|c|c|c|}
\hline \multicolumn{11}{|c|}{ Do you know if there is a link between periodontal diseases and pregnancy outcomes? } & \multirow[t]{3}{*}{ p-value } \\
\hline \multirow[t]{2}{*}{ Educational level } & \multicolumn{2}{|c|}{$\begin{array}{l}\text { Less than } \\
\text { high school }\end{array}$} & \multicolumn{2}{|c|}{ High school } & \multicolumn{2}{|c|}{ Diploma } & \multicolumn{2}{|c|}{ Bachelor } & \multicolumn{2}{|c|}{ Higher education } & \\
\hline & $N$ & $\%$ & $N$ & $\%$ & $N$ & $\%$ & $N$ & $\%$ & $\bar{N}$ & $\%$ & \\
\hline Yes & 6 & 7.5 & 18 & 22.5 & 1 & 18.8 & 33 & 41.3 & 8 & 10 & 0.010 \\
\hline No & 13 & 18.3 & 23 & 32.4 & 1 & 23.9 & 17 & 23.9 & 1 & 1.4 & \\
\hline
\end{tabular}

Table 4: Reported use of auxiliary dental hygiene devices and family income

\begin{tabular}{|c|c|c|c|c|c|}
\hline \multicolumn{6}{|c|}{ Do you use auxiliary dental hygiene devices (ex. Floss)? } \\
\hline \multirow[t]{2}{*}{ Family income by month (JD) } & \multicolumn{2}{|c|}{ Yes } & \multicolumn{2}{|c|}{ No } & \multirow[t]{2}{*}{$p$-value } \\
\hline & $N$ & $\%$ & $N$ & $\%$ & \\
\hline$<200$ & 5 & 29.4 & 12 & 70.6 & \\
\hline $200-400$ & 16 & 19.8 & 65 & 80.2 & \\
\hline $400-600$ & 8 & 28.6 & 20 & 71.4 & \\
\hline $600-800$ & 4 & 33.3 & 8 & 66.7 & \\
\hline$\geq 800$ & 7 & 63.6 & 4 & 36.4 & 0.04 \\
\hline
\end{tabular}

About $78.0 \%$ of pregnant women with bachelor degree reported having knowledge about the importance of dental consultation during pregnancy, while only $42.1 \%$ of pregnant women who have less than high school reported that they know about that, (Table 2).

Null hypothesis 2: Highly educated pregnant women would report less knowledge about the possible link between pregnancy and periodontal diseases than less educated pregnant women.

This null hypothesis was rejected, as Chi-square analysis showed a statistically significant relationship between educational level and knowledge about the possible link between pregnancy and periodontal diseases $(p=0.01)$. Almost $41.3 \%$ of pregnant women with a bachelor degree reported having knowledge about the existing of the possible link between pregnancy and periodontal diseases (Table 3 ).

Null hypothesis 3: Pregnant women with high income would report less using for the auxiliary dental hygiene devices than pregnant women with less income.

About $63.6 \%$ of pregnant women with high income are using auxiliary dental hygiene devices $(p=0.040)$, (Table 4$)$. Analysis revealed statistically significant relationship between income and using pregnant women for the auxiliary dental hygiene devices during pregnancy. Therefore, null hypothesis 3 was rejected.
Null hypothesis 4: Pregnant women with high income would report less using for dental services than pregnant women with less income.

Chi-square analysis revealed no statistically significant relationship between family income and routine dental visits during pregnancy $(p=0.149)$ (Table 5). Thus, the above null hypothesis was accepted.

Null hypothesis 5: Pregnant women with health insurance would report less using for dental services than pregnant women with no health insurance.

This null hypothesis was accepted as Chi-square analysis revealed no statistically significant relationship between having health insurance and using dental services during pregnancy $(\mathrm{p}=0.868)($ see Table 5).

\section{DISCUSSION}

A self-designed questionnaire was used to a total of 154 women aged between 18 and 40 years old who sought prenatal care at public health clinics and private clinics in the city of Irbid, Jordan. The 4 weeks' time frame of the study dictated the number of volunteers. To increase the returned rate of this study; the principals investigators stayed at the site and assistants collected the completed forms; this procedure allowed achieving a good return rate of about $99.4 \%$. As the assessment of knowledge, practice, 
Table 5: Routine dental visits during pregnancy

\begin{tabular}{|c|c|c|c|c|c|c|c|c|c|}
\hline \multirow[t]{2}{*}{ Health insurance } & \multicolumn{2}{|c|}{ Every 3 months } & \multicolumn{2}{|c|}{ Every 6 months } & \multicolumn{2}{|c|}{ When I feel pain } & \multicolumn{2}{|c|}{ I do not visit } & \multirow[t]{2}{*}{$p$-value } \\
\hline & $N$ & $\%$ & $\bar{N}$ & $\%$ & $N$ & $\%$ & $N$ & $\%$ & \\
\hline Insured & 4 & 5.7 & 7 & 10 & 29 & 41.4 & 30 & 42.9 & \\
\hline Uninsured & 3 & 4.2 & 5 & 6.9 & 33 & 45.8 & 31 & 43.1 & 0.868 \\
\hline \multicolumn{10}{|c|}{ Family income by month (JD) } \\
\hline$<200$ & 1 & 5.9 & 2 & 11.8 & 7 & 41.2 & 7 & 41.2 & \multirow{5}{*}{0.149} \\
\hline $200-400$ & 4 & 5.1 & 4 & 5.1 & 35 & 44.3 & 36 & 45.6 & \\
\hline $400-600$ & 2 & 7.1 & 3 & 10.7 & 11 & 39.3 & 12 & 42.9 & \\
\hline $600-800$ & 0 & 0 & 0 & 0 & 8 & 72.7 & 3 & 27.3 & \\
\hline$\geq 800$ & 0 & 0 & 4 & 36.4 & 4 & 36.4 & 3 & 27.3 & \\
\hline
\end{tabular}

and utilization of dental services during pregnancy in the present study was based on self-reports, the validity of the results might be questioned.

Three null hypotheses of this present study were rejected and two of them were accepted. Highly educated pregnant women have more knowledge about the possible link between pregnancy and periodontal diseases and have more knowledge also about the importance of dental consultation during pregnancy than less educated pregnant women. Furthermore, income was significantly associated with increase use of auxiliary dental hygiene devices. The average salaries of Jordanians are $\$ 1500$ about 1050 Jordanian Dinars (JD) ${ }^{13}$ Pregnant women with high income reported less using for dental services than those with less income. Furthermore, pregnant women with health insurance reported less using for dental services than pregnant women with no health insurance.

In the present study, the majority $62.4 \%$ of pregnant women brush their teeth regularly during pregnancy; this finding is lower than of those at Hamissi J et al ${ }^{4}$ study; which conducted in 2010; in which $70.3 \%$ of the participants brush their teeth regularly, and lower than of those at Thomas et $\mathrm{al}^{6}$ study; in which $91 \%$ of surveyed women stated that they brushed their teeth one or more times a day. This indicates a need to increase the awareness of oral hygiene practice among Jordanian pregnant women.

The reported findings indicated that educational level was significantly associated with the knowledge about the importance of dental consultation during pregnancy, $p=0.012$. About $42.1 \%$ of pregnant women who have less than high school reported that they knew about the importance of dental consultation during pregnancy which might suggest that they appreciate the importance of dental consultation during pregnancy.

It seems that the knowledge about the possible link between pregnancy and periodontal diseases increases along with the educational level of pregnant women. Current results indicated that $41.3 \%$ of pregnant women with a bachelor degree knew about a link between pregnancy and periodontal diseases, while only $7.5 \%$ of pregnant women with less than high school knew about that. This result is similar to a study done by Alwaeli et al, ${ }^{5}$ in which respondents with less educational level had difficulty in knowing what plaque is and its harms on periodontal tissue during pregnancy. As well as, Thomas et $\mathrm{al}^{6}$ reported similar findings, in which respondents with the university education reported better knowledge of periodontal diseases $(p<0.001)$ and dental plaque $(\mathrm{p}<0.03)$. This result also similar to what was reported by Habashneh et al ${ }^{10}$ in which they reported only $43 \%$ of the respondents were aware of the possibility relationship between pregnancy outcomes and oral health, and which was restricted to highly educated pregnant women.

In the present study, the majority of participants $53.2 \%$ had an awareness about the possible link between periodontal diseases and pregnancy outcomes, while in a previous study ${ }^{5}$ revealed that only $5.1 \%$ of the respondents believed there might be a relationship between gum diseases and premature labor; which indicated that pregnant women in the north of Jordan have valuable concern about possible link between oral health and pregnancy outcomes.

The percentage of participants with high income who reported that they use auxiliary dental hygiene devices ex. Floss was $63.6 \%$; and this is closely similar to that reported in another study. ${ }^{8}$ As well as, Thomas et $\mathrm{al}^{6}$ reported similar findings, in which women in the high socioeconomic index were more likely than other women to strongly agree that the use of dental floss would help in the prevention of periodontal disease $(p<0.02)$. It seems that cost is a factor that may reduce the number of Jordanian pregnant women who using auxiliary dental hygiene devices during pregnancy, as only $19.8 \%$ of pregnant women with low income reported using auxiliary dental hygiene devices, which may suggest their appreciation to the importance of practicing good oral hygiene during pregnancy.

Pregnant women with high income reported less using of dental services during pregnancy, $p=0.149$; however, Boggess et $\mathrm{al}^{8}$ reported that the economic status was associated with routine dental visits during pregnancy. The previous study ${ }^{8}$ was reported that the majority $74 \%$ of the 
participants having received no regular dental care during pregnancy, while, in the present study only $41.8 \%$ of the participant did not receive dental care during pregnancy. It seems that cost is not a factor that may reduce the number of visits to dental office during pregnancy among pregnant women in the north of Jordan as $42.4 \%$ of the respondents in this study expressed concern no need; while $23 \%$ of the respondents expressed because of pregnancy as reasons for not visiting dentist during pregnancy. This reason is similar and with lower percentage to which reported by Dinas et al, ${ }^{12}$ in which the majority $72.2 \%$ of the participants believed that dental treatment during pregnancy might have a negative effect on pregnancy outcome. That indicated; pregnant women in the north of Jordan may consider that dental treatment during pregnancy might not have a negative effect on pregnancy outcome.

It seems that having health insurance is not a factor that may increase the number of visits to dental office during pregnancy among pregnant women in the north of Jordan. As the reported findings of this study showed that having health insurance was no significantly associated with routine dental visits during pregnancy, $p=0.868$. This finding is almost different from which reported by Rochelle et al ${ }^{11}$ that women who receive dental care during pregnancy were more likely with low income and medicaid coverage. There were reasons affect on pregnant women use for the dental services in the north of Jordan during pregnancy, and these reasons are summarized in Table 1.

As a sample of the present study was chosen specifically in the north of Jordan, the findings of the present study may not be generalized to larger population.

\section{CONCLUSION}

Pregnant women in the north of Jordan use toothbrush to clean their teeth and gums, and they visit dentist occasionally, especially when they feel pain. Educational level was significantly associated with mothers' knowledge about the need for consultation and possible link between pregnancy and periodontal diseases with $p=0.012$ and $p=0.010$ respectively. Economic status has had a significant association with using auxiliary dental hygiene devices during pregnancy with $\mathrm{p}=0.040$ respectively.

Several factors may limit the validity of this study. Findings may not be generalized to larger population.
Moreover, there was no objective clinical examination of the subjects.

Further studies are needed to determine the actual prevalence of oral health problems during pregnancy. Educational preventive programs on oral self-care during pregnancy are recommended.

\section{REFERENCES}

1. Hajikazemi E, Oskouie F, Mohseny SH, Nikpour S, Haghany $\mathrm{H}$. The relationship between knowledge, attitude and practice of pregnant women about oral and dental care. European J Scientific Research 2008;24(4):556-562.

2. The Pregnancy Zone, How Poor Oral Hygiene Can Cause Pregnancy Gingivitis? Available at: www.thepregnancyzone. com. (Accessed 18, January, 2011).

3. Wrzosek T, Einarson A. Dental Care during Pregnancy. Canadian Family Physician 2009 June;55(6):598-599.

4. Hamissi J, BakianianVaziri P, Davalloo A. Evaluating oral hygiene knowledge and attitude of pregnant women. Iranian J Public Health 2010;39(1):28-31.

5. Alwaeli H, Al-Jundi S. Periodontal disease awareness among pregnant women and its relationship with sociodemographic variables. Int J Dent Hygiene 2005;3(2):74-82.

6. Thomas N, Middleton PH, Crowther C. Oral and dental health care practices in pregnant women in Australia: postnatal survey. Biomed Center Pregnancy and Children 2008;8:13. DOI: 10.1186/471-2393-2813.

7. Gaffield M, Gilbert B, Malvitz D, Romaguera R. Oral health during pregnancy: an analysis of information collected by the pregnancy risk assessment monitoring system. J Am Dental Association 2001;132(7):1009-1016.

8. Boggess K, Urlaub D, Massey K, Moos M, Matheson M, Lorenz C. Oral hygiene practices and dental service utilization among pregnant women. J Am Dental Association 2010;141(5):553-561.

9. Jiang P, Bargman E, Garrett N, DeVries A, Springman S, Riggs $\mathrm{SH}$. A comparison of dental service use among commercially insured women in minnesota before, during and after pregnancy. J Am Dental Association 2008;139(9):1173-1180.

10. Habashneh R, Guthmiller JM, Levy S, Johnson GK, Squier C, Dawson DV, Fang Q. Factors related to utilization of dental services during pregnancy. J Clini Periodontol 2005;32(7):815821.

11. Lydon-Rochelle M, Krakowiak P, Hujoel PH, Peters R. Dental care use and self - reported dental problems in relation to pregnancy. Am J Public Health 2004 May;94(5):765-771.

12. Dinas K, Achyropoulos V, Hatzipantelis E, Mavromatidis G, Zepiridis L, Theodoridis T, Dovas D, Tantanasis T, Goutzioulis F, Bontis J. Pregnancy and oral health: Utilization of Dental services during pregnancy in Northern Greece. Acta Obstet Gynecol Scand 2007;86(8):938-944.

13. $\$ 1500$ Average Salaries of Jordanians. See: www.sarayanews. com. (Accessed 29, April, 2012). 